\title{
Ritmo biológico das atividades forrageiras e de cuidado com a prole em Polistes canadensis (Linnaeus, 1758)
}

\section{Philippe Meirelles de Queiroz ${ }^{1}$; Miriam Gimenes²}

1. Bolsista PIBIC/Fapesb, Graduando em Biologia, Universidade Estadual de Feira de Santana, email: philipemeirelles@gmail.com

2. Orientadora, Departamento de Ciências Biológicas, Universidade Estadual de Feira de Santana, e-mail: mgimenes@uefs.br

PALAVRAS-CHAVE: Forrageio de vespas; ritmo de atividade; Polistes

\section{INTRODUÇÃO}

canadensis.

O ritmo biológico pode ser definido como qualquer evento biológico que se repete periodicamente no tempo e dessa forma altera seu estado de atividade e repouso ao longo do dia (TOMOTANI \& ODA, 2012). A manutenção desses ritmos mesmo sob condições de ausência de pistas ambientais cíclicas, indica a existência de osciladores circadianos associados a um sistema de temporização endógeno, responsável pelo comportamento rítmico do organismo (ENRIGHT, 1970; MOORE-EDE \& COLS., 1982).

Os trabalhos realizados demonstraram que animais invertebrados como os insetos (BECK, 1980; SAUNDERS, 1982) apresentam ritmo biológico e que podem ser influenciados pelo ciclo claro/escuro diário ou fotoperíodo anual. Foram realizados alguns estudos, comprovando a ritmicidade diurna nas atividades de vôos em Nannotrigona testaceicornis na Chapada Diamantina (SILVA \& GIMENES, 2015) e em Melipona scutellaris, Frieseomelitta doederleini (GOUW \& GIMENES, 2013), além de outras.

Em comunidades temperadas e tropicais, vespas sociais (Hymenoptera: Vespidae) são muitas vezes surpreendentemente abundantes. Elas recolhem água, fibras vegetais, carboidratos, e caçam presas de artrópodes (EDWARDS, 1980). As vespas sociais são forrageiras generalistas, mas os indivíduos são capazes de aprender e podem especializar-se pela caça de presas ou recolher outros recursos em locais específicos (RICHTER \& JEANNE, 1991).

Na região neotropical existe uma rica fauna em espécies de insetos sociais, dentre elas encontram-se as Vespidae (Polistinae) (RICHARDS, 1971; CARPENTER, 2004). A subfamília Polistinae apresenta atualmente cerca de 25 gêneros e mais de 900 espécies (CARPENTER, 2004), sendo divididos em três tribos comumente encontradas na região neotropical, que constituem Polistini, Mischocyttarini e Epiponini.

Os representantes da família Vespidae fornecem um bom modelo para estudos do ritmo de atividade no ninho, porque muitas das espécies como as dos gêneros: Agelaia (SAUSSURE, 1854 in FERREIRA, 2008), Apoica (VECHT, 1972), Polistes (FERREIRA, 2008), apresentam ninho aberto facilitando assim a visualização das diversas atividades exercidas no ninho. As vespas desta família apresentam comportamento social, com ampla variação de sistemas de organização colonial (WEST-EBERHARD, 1978).

O presente plano de trabalho se justifica pela sua nova visão a respeito do comportamento de alimentação e cria em vespas Polistes 
canadensis, acrescentando a dimensão temporal na análise dos comportamentos destes insetos, sendo assim o projeto tratará estes comportamentos de uma forma rítmica, identificando os fatores abióticos que mais influenciam as atividades.

\section{MATERIAL E MÉTODOS}

O estudo foi realizado no Campus da Universidade Estadual de Feira de Santana - UEFS ( $12^{\circ} 11^{\prime} 56.3^{\prime \prime} \mathrm{S}, 38^{\circ} 58^{\prime}$ 07.6" W), sendo localizado na cidade de Feira de Santana, Bahia, Brasil. O campus da UEFS, abrange uma área de $1,2 \mathrm{~km}^{2}$ (Santana \& Santos, 1999), inserido em uma zona de transição entre o domínio quente-úmido e o domínio de zona tropical, com uma estação seca definida no verão. Ao longo de seis meses de observação, entre novembro de 2015 a julho de 2016, durante três dias em cada mês, realizamos 15 minutos de observação em cada intervalo de hora por ninho, das 6:00 às 18:00 h (entre o nascer e o pôr do sol). As observações foram realizadas em pelo menos três ninhos de vespas em cada mês.

Para a quantificação das atividades totais e forrageiras foram observadas e contadas as vespas que chegavam e saiam da colônia sem material aparente e as que chegam carregando presas ou outro material. O perfil comportamental foi analisado através do forrageamento e cuidado com a prole realizado por meio de pouso com a presa, pouso com o líquido, pouso com polpa (FERREIRA et al., 2008). As observações foram realizadas em 9 colônias de $P$. canadensis, presentes no campus da UEFS, que foram filmadas para o registro das atividades das vespas durante o dia em diferentes condições de temperatura, intensidade luminosa e umidade relativa.

As análises do ritmo diário da atividade no ninho de $P$. canadensis, foram estudadas, através de testes de Rayleigh do Método da Estatística Circular (BATSCHELET, 1980; ZAR, 2010).

\section{RESULTADOS E DISCUSSÃO}

A temperatura média durante o tempo do estudo foi de $29,8^{\circ} \mathrm{C}$ e a umidade relativa média $77 \%$, enquanto a precipitação máxima de 242,2 $\mathrm{mm}$ em janeiro de 2016 e precipitação mínima de 1,8 mm no mês de dezembro de 2015.

\section{Condição dos ninhos e dados macroclimáticos}

Os ninhos observados, apresentaram número de indivíduos, de células de cria, e do número de atividade das vespas ativas, diferentes, ao longo dos meses. Os indivíduos ocuparam durante no máximo, de 3 meses o mesmo ninho. No mês de novembro foi observado o maior número de vespas entrando e saindo do ninho (670 atividades registradas) e o menor foi em junho (144 atividades registradas). Durante o mês de novembro foi observado que a temperatura estava elevada com média de $34,8^{\circ} \mathrm{C}$, e também baixa precipitação $(4,1 \mathrm{~mm})$ e baixa umidade relativa $(63 \%)$. No mês de Janeiro também foi observado um alto volume de atividade diária entrando (174 atividades registradas) e saindo (137 atividades registradas) dos ninhos, sendo que os valores de temperatura continuavam elevados $\left(31,3^{\circ} \mathrm{C}\right)$ e da umidade relativa alta $(89 \%)$, com os valores de precipitação pluviométrica também elevados $(225 \mathrm{~mm})$.

\section{Atividade diária das vespas}


As atividades diárias de todos os ninhos de $P$. canadensis observados tinham início às 6:00 h e terminavam às 18:00 h. Embora essas vespas apresentassem atividade marcadamente diurna observamos diferença nos horários das atividades entre os ninhos e entre os meses. Como nos meses de novembro, janeiro e abril em que as vespas iniciavam as atividades às 6:00 h, com luminosa média era de 12287 unidades Lux, enquanto nos meses de maio, junho e julho as atividades de forrageio do ninho começavam entre (7-9h).

A luminosidade média correspondente a $74,7 \%$ das atividades forrageiras de entrada no ninho, foi de 9.682 unidades Lux, enquanto $25,3 \%$ das atividades ocorreram ao longo de uma luminosidade média de 16.609 unidades Lux. A luminosidade média presente no ambiente enquando as vespas realizam suas atividades forrageiras de saída do ninho, correspondente a $73,6 \%$ do forrageio, apresentaram 9.665 unidades Lux, paralelamente $26,4 \%$ do forrageio de saída do ninho, possui luminosidade média de 17060 unidades Lux.

\section{Acrofase}

O teste de estatística circular mostrou que houve um horário preferencial das atividades diárias ao longo dos meses estudados, e estes foram significativos, porém com o valor de $r$ em torno de 0,7 , o significa dizer que os dados de atividade estavam dispersos durante o dia. Pelos dados de acrofase, podemos descrever uma faixa de horários preferenciais que variaram de 9:45 às 13:16 h para atividade de entrada e variavam de 9:25 às 13:48 h para atividade de saída.

\section{Discussão}

Os dados mostram que o comportamento das vespas $P$. canadensis, é muito complexo e extremamente dependentes de uma série de condições, como uma faixa de temperatura ideal $\left(31,5-45,4^{\circ} \mathrm{C}\right)$, na qual suas atividades de forrageamento são mais abundantes (10-19 atividades/15min). A luminosidade desempenha um papel crucial para que esses indivíduos possam se localizar saindo e retornando para o ninho, sendosua capacidade visual, diurna (WARRANT et al., 2006).

Ao longo dos meses (abril, maio, junho e julho), observou-se uma redução do número total de atividades forrageiras das vespas em relação aos meses de (janeiro e novenbro), com uma redução de 1,64 vezes. De forma geral, não observamos ritmo de atividade diária bem definido ao longo dos meses observados, o que provavelmente está associado ao tipo de dieta destas vespas, que é generalista, podendo ser larvas de insetos que estão presentes em momentos não definidos ao longo do dia (RAVERET-RICHTER, 2000; O'DONNELL, 1995; MORETTI et al., 2011 )

\section{CONSIDERAÇÕES FINAIS}

O forrageamento das colônias ao longo do ano pode representar a disponibilidade dos recursos presentes no ambiente, assim como uma demanda interna que poderia ser induzida tanto pela vespa dominante do ninho. Assim as condições de sombreamento e a presença dos predadores, poderiam influenciar no tempo de vida útil de cada colônia. Sugerindo que mais trabalhos sejam feitos, para que possamos identificar como a demanda ao forrageio surge e quais os fatores que mais estariam relacionados com o constante comportamento de abandono dos ninhos e a construção de novos ninhos. 


\section{REFERÊNCIAS}

BATSCHELET, E. 1980. Circular Statistics in Biology. London: Academic Press, 371p.

BECK, S. D. 1983. Insect thermoperiodism. Annual Reviews of Entomology, 28: 9-108.

CARPENTER, J. M. 2004. Synonymy of the genus Marimbonda Richards, 1978, with Leipomeles Möbius, 1856 (Hymenoptera: Vespidae: Polistinae), and a new key to the genera of paper wasps of the new world. American Museum Novitates, 3465: 1-16.

EDWARDS R. 1980. Social Wasps: Their Biology and Control. Sussex, UK: Rentokil. 398p.

ENRIGHT, J.T. 1970. Ecological Aspects of Endogenous Rhythmicity. Annual Review of Ecology and Systematics 1: 221-238.

FERREIRA, E.V.; SANTOS, I.A.; SCHOEREDER, J.H.; SERRÃO, J.E.; CAMPOS, L.A.O.; LINO-NETO, J. 2008. Insetos sociais: da biologia à aplicação - Viçosa, MG: Ed. UFV, 442p.

GOUW, S.M.; GIMENES, M. 2013. Differences of the Daily Flight Activity Rhythm in two Neotropical Stingless Bees (Hymenoptera, Apidae). Sociobiology 60(2): 183-189.

MOORE-EDE, M., SULZMAN, F. M. \& FULLER, C. A., 1982. The Clocks That Time Us: Physiology of the Circadian Timing System. Commonwealth Fund Publications. Harvard University Press.

MORETTI, T. C.; GIANNOTTI, E.; THYSSEN, P. J.; SOLIS, D. R.; GODOY, W. A. C. 2011. Bait and habitat preferences, and temporal variability of social wasps (Hymenoptera: Vespidae) attracted to vertebrate carrion. Journal of Medical Entomology, 48: 1069-1075.

O'DONNELL, S. 1995. Necrophagy by neotropical swarm-founding wasps (Hymenoptera: Vespidae, Epiponini). Biotropica, 27: 133-136.

RAVERET-RICHTER, M. 2000. Social wasp (Hymenoptera: Vespidae) foraging behavior. Annual Review of Entomology, 45: 121-150.

RICHARDS, O. W. 1971. The biology of the social wasps (Hymenoptera:Vespidae). Biological Reviews, 46: 483-528.

SAUNDERS, D. S. (1982) Insect clocks, 2nd ed. Pergamon Press, NY.

SILVA, W. P., GIMENES, M. 2015. Pattern of the daily flight activity in two colonies of Nannotrigona testaceicornis (Lepeletier, 1836) (Hymenoptera, Apidae) in different conditions in the Brazilian semiarid region. Sociobiology, v. 61, p. 547-553.

TOMOTANI B. M. \& ODA A. G. 2012. Diurnos ou Noturnos? Discutindo padrões temporais de atividade. Revista da Biologia 9(3): 1-6.

VECHT, J.;VAN DER. 1972. The social wasps (Vespidae) collected in French Guyana by the mission du Muséum National d'Historie Naturelle with notes on the genus Apoica Lepeletier. Annales Societe Entomolique de France 8: 735-743.

Warrant, E. J., Kelber, A., Wallén, R., \& Wcislo, W. T. 2006. Ocellar optics in nocturnal and diurnal bees and wasps. Arthropod structure \& development, 35(4), 293-305.

WEST-EBERHARD, M.J. 1978. Temporary queens in Metapolybia wasps: nonreprodutive helpers without altruism? Science, 200:441-443.

ZAR, JH. 2010. Biostatistical analysis. 5. ed. Prentice-Hall, Upper Saddle River, New Jersey, p. 944. 